\title{
PROPOSTA DE IMPLEMENTAÇÃO KAIZEN NA GESTÃO DE ESTOQUES: ESTUDO DE CASO NA EMPRESA SAMAÚMA DISTRIBUIDORA
}

\section{ARTIGO ORIGINAL}

OLIVEIRA, Maria Socorro Silva de ${ }^{1}$, BARBOZA, Ronnier Anderson de Araújo², GUEDES, Suellen Peixoto Costa ${ }^{3}$, ROBERTO, José Carlos Alves ${ }^{4}$

OLIVEIRA, Maria Socorro Silva de. et al. Proposta de implementação Kaizen na gestão de estoques: estudo de caso na empresa Samaúma Distribuidora. Revista Científica Multidisciplinar Núcleo do Conhecimento. Ano. 06, Ed. 10, Vol. 03, pp. 120-144. Outubro 2021. ISSN: 2448-0959, Link de acesso: https://www.nucleodoconhecimento.com.br/administracao/gestao-de-estoques, DOI: 10.32749/nucleodoconhecimento.com.br/administracao/gestao-de-estoques

\section{RESUMO}

O presente artigo se desenvolveu através de um estudo de caso no Centro de Distribuição Samaúma Distribuidora de Autopeças LTDA. - SPE, destacando que esta atua efetuando atividades de serviços automotivos e enquadra-se em pequeno porte. A íntegra, o estudo visa investigar e compreender o problema de pesquisa que consiste em: como a inserção de técnicas japonesas de gerenciamento no Centro de Distribuição da Somaza podem desenvolver melhorias na produtividade do setor de estoque do Grupo? Logo, o objetivo geral descreve-se em elaborar uma proposta de implementação no modelo Kaizen na organização, já os objetivos específicos consistem em identificar o processo e introdução da ferramenta, analisar as causas evidenciadas de problemas quais podem ser solucionados através de

\footnotetext{
${ }^{1}$ Graduanda do curso de Administração.

${ }^{2}$ Graduando do curso de Administração.

${ }^{3}$ Graduanda do curso de Administração.

${ }^{4}$ Orientador. Mestrado profissional em Engenharia de produção. Especialização em Gestão em Logística empresarial. Graduação em Administração com Ênfase em Marketing.
}

RC: 98782

Disponível em: https://www.nucleodoconhecimento.com.br/administracao/gestao-deestoques 
ações desta metodologia e propor a introdução de eventos desta para engajamento nos departamentos necessários. O estudo é fundamentado no Diagnóstico Organizacional que salienta o setor logístico com a maior criticidade. Esta pesquisa é de caráter qualitativo e cunho exploratório. Seguindo-se normas e procedimentos, realiza-se avaliação de todas as ações propostas por meio da ferramenta $5 \mathrm{~W} 2 \mathrm{H}$, onde com detalhamento apresenta-se como deve abordar-se intervenções. O correto o uso da metodologia Kaizen e outras de técnicas de gerenciamento oriundas do Japão, proporcionam aos colaboradores da Somaza uma visão panorâmica, alinhada e precisa da correlata localidade dos bens e aparatos, tornando ágil o fornecimento dos serviços e elevando o conceito de excelência dos consumidores, e assim, aprimorando o atendimento ao público geral do Grupo Somaza.

Palavras-chave: Proposta, Logística, Autopeças.

\section{INTRODUÇÃO}

O segmento varejista de autopeças é englobado pelo ramo automotivo, o que faz com que este necessite sempre estar a par de todas as inovações que em demasiada rapidez geram a obsolescência dos produtos. Desta forma, apresenta-se o presente estudo de caso executado por meio da Diagnose Empresarial na empresa Samaúma Distribuidora de Autopeças LTDA. - SPE, que atua neste ramo.

Condizente a investigação empresarial em questão, verifica-se que na empresa a logística, em destaque os estoques, requer atenção diferenciada do gestor. Ao considerar-se que os processos neste setor se apresentavam em completa desordem, nulo o controle do estoque, o atendimento sendo abordado como não prioritário e a reposição de itens as filiais, desordenada. Destaca-se que com a descoberta destas consideráveis adversidades, manifesta-se a necessidade de elaborar uma proposta de implementação do modelo Kaizen na organização.

RC: 98782

Disponível em: https://www.nucleodoconhecimento.com.br/administracao/gestao-deestoques 
Menezes et al. (2019) declara que ao delimitar-se um tema de estudo, deve-se constituir um questionamento de pesquisa para embasar o desenvolvimento da pesquisa, no entanto, nem sempre este questionamento apresenta-se em forma de problemática, porém, deve ser abordado como tal. Portanto, o presente artigo dedica-se a solucionar a indagação inicial de: como a inserção de técnicas japonesas de gerenciamento do Centro de Distribuição da Somaza podem desenvolver melhorias na produtividade do setor de estoque do Grupo?

A orientação para o desenlace e deliberação da problemática abordada, desenvolve a necessidade de seguir-se uma metodologia específica, assim o estudo aplica-se por métodos qualitativos, de cunho exploratório e por meios bibliográficos.

Estudos relevantes ao ramo de autopeças, são relativamente novos. Mediante a isto, o artigo aqui exposto identifica o processo e introduz a ferramenta Kaizen, além de analisar as causas e evidenciar as problemáticas que podem ser solucionados por meio da metodologia e propor a introdução dos conceitos nos departamentos necessários. Para concretizar essas ações, recorreu-se ao detalhamento por meio da ferramenta $5 \mathrm{~W} 2 \mathrm{H}$, onde se aponta além do método KAIZEN as ferramentas de qualidade 8S, PDCA e Curva ABC. As quais desenvolvem melhorias contínuas, sensos colaborativos e organização dos estoques para conceber máximo aproveitamento dos ambientes e aprimorar o giro dos itens.

Espera-se que com introdução destas propostas metodológicas, ocorra melhor engajamento nos departamentos. Onde haja maior satisfação dos públicos, produção de agilidade no tempo de resposta às solicitações dos sócios e clientes, além de sanar todas as falhas identificadas no setor de logística da instituição, o que contribui fortemente para o funcionamento da instituição.

\section{FUNDAMENTAÇÃO TEÓRICA}

Conforme Silva (2014, p. 17) a fase de embasamento ao abordado no estudo "[...] indica o caminho que o pesquisador está adotando para a realização de seu estudo,

RC: 98782

Disponível em: https://www.nucleodoconhecimento.com.br/administracao/gestao-deestoques 
possibilitando a outros estudiosos a comprovação dos resultados, [...] bem como a replicação $[\ldots] "$.

Shitsuka et al. (2018) afirma que o embasamento literário de um estudo, deve ser guiado apenas por autores realmente conhecedores do assunto, que possam abordar e discutir corretamente o tema. Afinal, os resultados são confirmados ou refutados com base nesta fundamentação de literatura.

Deste modo, recorre-se a estudos anteriormente desenvolvidos, no intuito de embasar cada possível nova descoberta e demonstrar quais passos o pesquisador deve tomar e quais possíveis dificuldades este terá no decorrer da pesquisa.

\subsection{LOGÍSTICA}

No desenvolvimento e transformação no que atualmente é o conceito de logística que se reconhece no mundo corporativo, houve a introdução e influência externas de diversos ambientes, porém, o militarismo é o que se destaca. A introdução da palavra surge a partir do século XVII como "logistique", termo que inicialmente representava uma derivação de titulação no exército francês, ao qual era associado ao responsável pelo controle do deslocamento e dos ambientes de estadia das tropas operantes. No entanto, somente a partir da Segunda Guerra Mundial, foi que a designação de logística demonstrou maior semelhança com o que se aborda atualmente.

Segundo Carvalho (2013) compreende-se que a logística de uma empresa envolve o gerenciamento de transporte, direcionamento, forma adequada de alocar produtos, matérias-primas, embalagens, transitórios no depósito, conforme fluxo de produção e pedidos.

Para a autora Godoy (2013, p. 16) o conceito de logística envolve o ato de "[...] gerenciar os fluxos de informações que movimentam os produtos buscando atingir níveis de serviços satisfatórios aos clientes a preços razoáveis, preocupando-se inclusive com a destinação final dos produtos pós-consumo [...]".

RC: 98782

Disponível em: https://www.nucleodoconhecimento.com.br/administracao/gestao-deestoques 


\subsubsection{CONCEITO DE ESTOQUE}

Em geral, as instituições, desde as prestadoras de serviço até as produtoras, agregam algum ambiente em suas instalações, onde aloca seus materiais, equipamentos e insumos, produtivos ou não.

Silva e Oliveira (2014, p. 01-02) pode-se conceituar o estoque "[...] como representativo de matérias-primas, produtos semiacabados, componentes para montagem, sobressalentes, produtos acabados, materiais administrativos e suprimentos variados".

Sendo assim, conforme Martelli e Dandaro (2015) descreve-se que os estoques devem atuar como gerenciadores do fluxo, ou seja, regular o período tanto de entrada dos insumos quanto de saída de materiais produzidos, bem como compreender onde há variações.

\subsubsection{CLASSIFICAÇÃO ABC}

Desenvolvida em 1897 pelo ecônomo italiano Vilfredo Pareto, atua como classificadora dos produtos e de sua conforme atenção dos gerenciadores.

Vago et al. (2013) aponta que Pareto desenvolveu um estudo estatístico que se tornou a base introdutória ao preceito que é atualmente reconhecido como Curva ABC. O estudo demonstrava a taxa dos proventos de uma nação, demonstrando que do produto final, apenas uma pequena parcela era de posse da população geral.

Conforme Souza et al. (2015) pode-se afirmar que em um estoque com diversas peças, buscar manualmente itens específicos, torna-se uma atividade trabalhosa e ocasiona perda de tempo valioso dos controladores. Desta forma, a metodologia $A B C$ é uma ótima auxiliadora do gerenciamento de estoque, afinal esta compreende quais produtos são responsáveis pelos maiores lucros internos. 


\subsubsection{ESTRATÉGIAS DE ARMAZENAGEM}

Para os autores Spejorim e Junior (2012) identifica-se armazenagem como a estocagem de itens como: matéria-prima ou peças em produção, ou finalizadas que possui como finalidade a disponibilidade de provisões aos clientes e a produção. As decisões devem seguir padrões, para não comprometer as deliberações de depósitos, de trabalhadores temporários, ou até mesmo a forma de conduzir a parte tecnológica no manuseio de seus pedidos, sem intervir no andamento do armazém.

$\mathrm{O}$ ato de armazenar remonta os primórdios da humanidade, eras antes da sociedade moderna, um dos primeiros registros denotam 1700 a.C., onde sem qualquer conceito logístico os faraós efetuavam armazenagem de grãos para o período de maior seca. No entanto, foi somente com a Revolução Industrial que o termo foi considerado como depósito, não se reconhecia a demanda e conceito de just in time, pois era inexistente.

Com o avançar da modernidade compreende-se que, para manter-se com vantagem competitiva atualmente, é necessário possuir planejamento logístico que possibilite a compreensão de: o que, como e quando realizar as produções operacionais.

Vago et al. (2013, p. 640) declaram que "[...] quando o gestor conhece a demanda dos itens, é possível realizar um gerenciamento eficiente para suprir o consumo do estoque, permitindo, assim, a aquisição somente do que for necessário para determinado período [...]".

\subsubsection{LOGÍSTICA ENXUTA}

Magno e Ferreira (2013, p. 127) declaram que esta metodologia de logística enxuta "[...] visa implementar um sistema puxado com reposição nivelada e frequente, em pequenos lotes ao longo do fluxo de valor da cadeia de suprimentos para trabalhar a forma mais sincronizada possível de acordo com o consumo da área".

RC: 98782

Disponível em: https://www.nucleodoconhecimento.com.br/administracao/gestao-deestoques 
Inicialmente é necessário compreender o conceito de pensamento enxuto, sendo assim, este compreende-se pela forma de refletir sobre quais reprojetos e melhorias podem ser agregadas a instituição, buscando reduzir a zero o grau de desperdícios e sempre almejando dar por realizadas as necessidades e desejos dos consumidores.

Já na logística enxuta, isto implica em inserir as concepções do Sistema Toyota de Produção, para melhorias contínuas nas operações e na cadeia de suprimentos. Sendo assim, de acordo com Pádua e Garcia (2019) este preceito nada mais é do que planejar e operacionalizar os processos de: suprimentos, com gerenciamento de estoque; internos, com o fluxo de materiais e produtos conclusos em todos os ambientes da empresa; de distribuição, com o gerenciamento de saída do produto da organização ao consumidor e; reversos, atuando com o retorno de todos os produtos ou itens que agregam o produto, ao ambiente produtivo ou ao de devido descarte.

Abordar a logística reversa nos processos logísticos de uma empresa, descreve que esta política não aborda apenas as operações, no entanto, aplica-se a todos os setores, atingindo-os direta ou indiretamente.

\subsection{KAIZEN}

A metodologia atualmente conhecida como Kaizen, origina-se da junção dos termos japoneses "Kai" e "Zen", que significam consecutivamente, "mudança" e "melhor", por tanto, melhoria contínua, esta requer o envolvimento de todos os ramos da instituição.

Kuribayashi (2018) afirma que instigar preceitos que ampliam o progresso e o melhor desenvolvimento das atividades na empresa é dever do gestor, examinar a fundo as falhas de modo a encontrar as raízes de sua causa conduz-se necessário a desenvolver as melhorias contínuas em todos os âmbitos empresariais.

RC: 98782

Disponível em: https://www.nucleodoconhecimento.com.br/administracao/gestao-deestoques 
Aplicando-se no operacional, tático e estratégico para melhor desenvolver as operações internas, geralmente, gestores e colaboradores devem atuar com 0 pensamento de "poucos gastos". O método é tão producente no intuito de reduzir custos, que os japoneses o utilizam em seu cotidiano, sem estes nem mesmo notarem.

De acordo com Silva et al. (2018) o conceito de Kaizen distingue-se de inovação, por Kaizen buscar transformações primorosas, relacionadas ao capital humano, como renovações em comunicação e treinamento. Já inovação requer modificações radicais, como adesão grandiosa de tecnologias e equipamentos, onde os gastos são exorbitantes.

\subsubsection{JUST IN TIME}

A metodologia originária do termo da língua inglesa Just in Time, possui o significado literal de "no momento certo" ou "justo a tempo". É a doutrina de fábrica que a instituição visa produzir na quantidade certa para suprir a demanda, adquirindo matéria-prima no tempo exato e fornecendo o produto na data combinada. Produzindo mediante as demandas, sem a necessidade de estocar.

O conceito surgiu no Japão nos anos 70 , baseado na metodologia abordada pela Toyota Motor Company, a qual o foco mostrava-se no controle e coordenação dos sistemas produtivos, possibilitando atender demandas específicas.

Conforme Santos (2014) categoriza-se que os gestores se pautam no conceito de que no Just in time, em seus armazéns. Devem compreender que estes são esconderijos para possíveis falhas de processos, deste modo, o enfoque principal da metodologia é dizimar estes volumes e viabilizar a constatação detalhada dos verdadeiros problemas organizacionais, possibilitando sua erradicação.

RC: 98782

Disponível em: https://www.nucleodoconhecimento.com.br/administracao/gestao-deestoques 


\subsubsection{CONCEITO DE KAIZEN}

Silva et al. (2018) ressalta que a metodologia não busca apenas as grandes transformações. Na verdade, para o autor, o conceito de Kaizen relata que qualquer benfeitoria realizada, por menor que seja, quando unificada as demais dos subsequentes ramos da corporação, transcrevem-se em grandes efeitos, deste modo, não se espera apenas por gigantescas modificações, as transformações ocorrem diariamente e através de cada indivíduo.

Kuribayashi (2018, p. 18) declara que "o Kaizen é definido como um sistema de contínuo, melhoramento e envolvimento de todos da organização, desde o gerente a colaboradores [...]".

Como já descrito, Kaizen é uma expressão de procedência japonesa que descreve o conceito de constante mudança para melhor, aplicada para divulgar o conhecimento de melhoria contínua na vida, seja ela em particular, coletiva ou laboral. $\mathrm{Na}$ conjuntura empresarial o Kaizen trata-se de um método usado para reduzir os custos e aprimorar a produtividade.

Segundo Loos e Fontes (2017), a metodologia Kaizen descreve vários métodos de gerenciamento e inovação que anteriormente concebiam-se isoladamente, sendo elas:

- Automação;

- Colaboração contínua entre administração e "chão de fábrica";

- Controle, gerenciamento, aperfeiçoamento e círculos da Qualidade;

- Desenvolvimento de Novos Produtos;

- Disciplina nas atividades;

- Manutenção e aperfeiçoamento da Produtividade;

- Metodologia Just in Time e Kanban;

- Orientação ao Consumidor;

- Preceitos de zero Defeitos;

RC: 98782

Disponível em: https://www.nucleodoconhecimento.com.br/administracao/gestao-deestoques 
- Produção em Grupos Pequenos e;

- Sistemas de sugestões e robótica.

\subsubsection{ETAPAS E IMPLEMENTAÇÃO DE UM PROGRAMA KAIZEN}

Por ser considerado um método de constante transformação e melhora, a aplicabilidade aborda a todos os ramos do mercado, de modo que, cada segmento deve adaptar-se e utilizar dos preceitos sabiamente.

As indicações do autor Ito (2012) observância do modelo Kaizen abrange todos na organização, e descreve que as melhorias devem ser provenientes do empenho de todos. Neste método a colaboração de pessoal é imprescindível, estes devem produzir por meios sugestivos quais seus pensamentos sobre quais formas de melhorias estes visualizam para a organização, isto de certa forma motiva-os e transcreve-se em diversas decorrências efetivas.

O autor completa que se efetua necessário o auxílio de outras ferramentas de qualidade, ferramentas estas que colaboram no reconhecimento da fonte das falhas e planos de ações que desenvolvam resoluções as problemáticas manifestadas.

Contudo, ao aderir-se a metodologia do Kaizen, compreende-se que o principal desejo é reduzir os desperdícios. Para a adesão, conforme Fornelos (2016) viabilizam-se dois modos de procedência, sendo:

- Primeiro: Implantá-lo inicialmente em uma única equipe destacada como "equipe piloto" e posteriormente aplicar simultaneamente nos demais setores, ou;

- Segundo: Destacar uma equipe e transcrever a estes os conceitos Kaizen e estes com a base de conhecimento necessária, desenvolvem a aplicação interna. 
Constata-se que este método foi o que se correspondeu melhor aos anseios e expectativas da empresa, por tanto, optou-se pela sua adesão na produção deste estudo.

\subsubsection{CICLO PDCA}

O desenvolvimento desta ferramenta ocorreu em meados dos anos 30 por Walter Andrew Shewhart, no entanto, somente quando William Edwards Deming introduziu o método nas grandes organizações japonesas que este ganhou força de propagação.

Elaborado inicialmente com o foco no controle estatístico, no entanto, sempre com a possibilidade de aplicação em qualquer etapa para solução de problemáticas. Contudo, o PDCA é atualmente concebido por ciclos e é um dos recursos de gerenciamento mais utilizado na tomada de decisões empresariais, buscando os melhores resultados nas metas estabelecidas.

Atua como guia organizacional, direcionando quais "rotas" os gestores devem seguir para solução das complicações institucionais. Com a desenvoltura destes procedimentos, aplicar métodos de capacitação para fiel realização do estipulado é primordial e garante a correta execução das atividades.

Para Kuribayashi (2018, p. 23) "as etapas do ciclo PDCA são denominadas como: Planejar, executar, verificar e agir, sendo objetiva e simples suas ações dentro da organização [...]".

Para Cunha (2012) a série de procedimentos desta ferramenta, necessitam ser empregadas com seriedade para correção das problemáticas. Inicialmente: planejar, tudo a efetuar-se, determinar-se os resultados esperados; executar, todas as atividades devem ser efetivadas conforme o pré-estabelecido; verificar, os proveitos e quais os procedimentos tornaram possíveis os resultados e agir, produzindo ações de aperfeiçoamento. 


\subsubsection{BRAINSTORMING}

Define-se brainstorming como um conjunto de técnicas e procedimentos que possuem o intuito de incentivar o aparecimento de soluções inovadoras. Quanto maior o número de pareceres, maior será a quantidade de ideias para resolução das problemáticas da companhia.

Ito (2012) transcreve o conceito de brainstorming concebeu-se quase ao fim da década de 30 e o termo possui a tradução de "tempestade cerebral". Ou seja, é utilizado como método para produção de sugestões, seu desenvolvimento é abordado em agrupamento e proporciona resoluções criativas.

O conceito refere-se a uma prática que envolve inúmeras pessoas, é muito utilizado em diversas entidades com o propósito de solucionar determinado problema, o procedimento engloba opiniões ou projetos que somados ativam a criatividade. Teza et al. (2017) descrevem que o brainstorming transcreve a viabilidade de exposição das ideias das equipes na organização, isto sem qualquer risco de criticidade, ao contrário, deseja-se que estas equipes demonstrem suas opiniões para produção de soluções as carências expostas.

\subsubsection{S}

Com o sucesso da metodologia $5 \mathrm{~s}$ no mundo corporativo oriental, buscou-se inserila da mesma maneira no mundo ocidental, no entanto, o sistema demonstrou-se falho por conta da grande diferença cultural que aqui predomina.

Neste conceito de 5s, conforme os autores Santos e Bruno (2019, p. 03) "os sensos fazem referências às palavras japonesas, iniciadas com a letra "S": SEIRI, SEITON, SEISO, SEIKETSU e SHITSUKE, que caracterizam os sensos que a organização deve se orientar [...]".

Desejando implementar nas instituições esta cultura, ajustes foram necessários dando origem ao $8 \mathrm{~S}$, ou seja, somados a mais 3 sensos que integralizam aos 
antecedentes desta ferramenta com técnicas japonesas. De acordo com Matsumoto e Culchesk (2017) o programa desenvolve-se ansiando qualificar e disciplinar os colaboradores, desenvolvendo as incumbências por vias metódicas e progressistas.

\subsubsection{PARCERIAS CLIENTE-FORNECEDOR}

Atualmente com a revolução e inovação é perceptível a mudança entre clientefornecedor, devido ao enorme grau de confiança e segurança, gerou-se uma parceria mais sólida entre ambos, baseado no respeito e pontualidade nas entregas dos produtos e nos serviços prestados com qualidade.

Souza e Rainho (2013) determinam que a atualização constante a qual encontra-se o planeta, deve produzir novas formas de como os gerenciadores empresariais devem lidar com a relação fornecedor-cliente e a concorrência que esta acarreta. Compreende-se que, somente através da redução de vantagens competitivas dos adversários que, realmente ocorrem vantagens competitivas a uma instituição específica.

Zorzenon (2019) declara que essas relações envolvem constante renovação, isto, por de certo modo os fornecedores acabam por participar do processo de formatação dos itens.

Já para Cardoso (2012) na relação entre clientes e fornecedor existe a primordialidade da organização produzir e manter conexões seguras e sensatas, tanto interna quanto externamente, isto para garantir sua segurança no seu ramo de atuação.

\subsubsection{FERRAMENTAS DA QUALIDADE}

Conceituam-se como procedimentos que intencionam determinar, precisar, analisar e cogitar soluções que influenciam no andamento positivo dos procedimentos trabalhados, facilitando a melhoria do monitoramento dos processos, bem como as tomadas de decisões.

RC: 98782

Disponível em: https://www.nucleodoconhecimento.com.br/administracao/gestao-deestoques 
Murback e Daniel (2014) afirmam que nos últimos tempos o que mais se busca no meio corporativo é a qualidade e a alacridade dos stakeholders, pois se compreende que isto transcreve-se em superioridade corporativa. Os autores completam declarando que a qualidade tomou forma a partir da $2^{\text {a }}$ Guerra Mundial, onde procedimentos metodológicos específicos descreviam respostas eficazes, transformando o conceito de qualidade em uma disciplina reconhecida e almejada no mundo corporativo.

Segundo Silva et al. (2016, p. 34) quanto às ferramentas, "estes recursos podem ser usados tanto numa grande empresa como na mais simples delas, tendo como característica comum o uso de uma ferramenta gráfica e pessoas capacitadas para analisar criticamente os resultados obtidos [...]".

\section{MATERIAIS E MÉTODOS}

O conhecimento deve ser conquistado continuamente, sempre através de técnicas e métodos que são necessários tanto para validação destes conhecimentos, quanto para sua melhor compreensão.

Para confirmar Shitsuka et al. (2018, p. 67) declaram que "método é o caminho para se realizar alguma coisa e quando se tem o caminho, torna-se mais fácil realizar viagens sabendo onde se está e aonde se quer chegar e como fazê-lo [...]".

\subsection{PROCEDIMENTOS METODOLÓGICOS}

Por vezes as maiores dificuldades dos acadêmicos apresentam-se pela falta de conhecimento das metodologias necessárias a propagação de qualquer forma de informação. Neste sentido, para os autores Santana e Encinas (2019) entende-se que, o ato de buscar novos conhecimentos é direcionado pelo valer-se de técnicas, diretrizes e instrumentos que auxiliam na descoberta das reais causas de determinada conjuntura. Esta coleção de passos, determina qual a metodologia mais viável a realizar descobertas verídicas, nas mais diversas áreas científicas. 


\subsubsection{QUANTO À NATUREZA}

Com o desenvolver constante das ciências, compreendeu-se que utilizar apenas a técnica quantitativa não era suficiente para abordar áreas específicas da ciência, deste modo surgiu o método qualitativo, que aborda a complexidade das diversas variáveis da educação. Schneider, et al. (2017, p. 570) corroboram com esta afirmação descrevendo seu crescimento por conta da "[...] complexidade e dinâmica dos fenômenos envolvidos e as dificuldades na manipulação de variáveis [...]".

De acordo com Paschoarelli et al. (2015, p. 69) algumas das principais características do método qualitativo "[...] são: foco na interpretação e não na quantificação; ênfase na subjetividade; o processo de pesquisa é flexível; maior interesse pelo processo do que pelos resultados; [...]".

Deste modo, por este estudo apresentar mais proximidade dos pesquisadores com o objeto de pesquisa, recorreu-se ao método qualitativo para seu desenvolvimento.

\subsubsection{QUANTO AOS FINS}

Conforme os autores Munaretto, et al. (2013, p. 10) "[...] as pesquisas exploratórias são úteis quando o tema em estudo foi pouco explorado [...]".

Já para Pereira e Lima (2018) nota-se que habitualmente inicia-se esse modelo de pesquisa, recorrendo-se a pesquisas bibliográficas para obter-se embasamento.

Por tanto, neste estudo adotou-se o método exploratório de pesquisa, pois a organização não apresentou grandes dados de referência, no entanto, conforme este material foi produzido, determinaram-se os dados aqui apresentados e confirmados por bibliografia.

RC: 98782

Disponível em: https://www.nucleodoconhecimento.com.br/administracao/gestao-de$\underline{\text { estoques }}$ 


\subsubsection{QUANTO AOS MEIOS}

Para os autores Pereira e Lima (2018, p. 99) "[...] pesquisa bibliográfica baseia-se em material já desenvolvido, principalmente livros e artigos [...]".

Contudo, Treinta et al. (2014, p. 508) descrevem que se deve "[...] estabelecer uma estratégia [...] que tanto facilite a identificação [...] como garanta a capacidade de estabelecer as fronteiras do conhecimento advindo dos achados científicos [...]"

Sendo assim, como já descrito anteriormente a abordagem dos meios desta sapiência, ocorreu através do método de pesquisa bibliográfica, onde diversos autores renomados foram citados.

\subsection{CARACTERIZAÇÃO DA EMPRESA}

O atual estudo elaborou-se através de uma única fase, concebido na Samaúma Distribuidora de Autopeças LTDA. - SPE, que possui o nome fantasia de SOMAZA e sua sede localiza-se na Av. Samaúma, 101 A, no bairro Monte das Oliveiras, na cidade de Manaus/AM - CEP: 69.093-132.

A instituição atua no setor terciário de mercado, ao qual engloba prestação de serviços e comércio geral. A sociedade SOMAZA originou-se no dia 27 de outubro de 2000 e contou com a presença de 10 profissionais com vasta experiência no campo automobilístico regional, onde no ato 8 sócios apresentaram-se como assinantes de contrato, dos quais o número duplicou e continuou a crescer, de modo que atualmente no ano de 2021 agrega o total de 22 associados, 11 colaboradores e um Centro de Distribuição (CD) com mais outras 23 filiais.

Seu catálogo de produtos é diversificado, destacando-se: baterias, pneus, kit de amortecedores e embreagem, óleo para motor, discos e pastilhas de freio, rolamentos, lâmpadas, filtro de óleo e de freio. Aos quais se originam das mais diversas marcas, como: Bridgestone, Fortlub, Moura e 3M. 
Quanto às características físicas da instituição sua área construída agrega a medida de 2.760,96 $\mathrm{m}^{2}$, subdivididos em escritório geral e sala de reuniões e 1 galpão de $1.000,00 \mathrm{~m}^{2}$.

A primazia do grupo é facilitar negociações sempre transpondo expectativas, de modo que no mercado evolutivo todos possam adquirir seus desejos e/ou necessidades com máxima acessibilidade de preços e qualidade.

\section{RESULTADOS E DISCUSSÕES}

Com base nos estudos realizados, através da pesquisa de campo elaborada por meio do Diagnóstico Organizacional desenvolvido na Empresa Samaúma Distribuidora de Autopeças LTDA. SPE, averiguou-se a necessidade de intervenções internas em setores específicos.

Salienta-se que, embasado no Diagnóstico Organizacional abordado na SOMAZA, apresentam-se métodos para resolução das falhas encontradas no setor de logística da instituição, abordando o estoque com maior foco. Em sequência desenvolve-se como objetivo central, melhores conquistas produtivas e consequentemente aumento nos rendimentos organizacionais.

A empresa em estudo agrega pontos específicos e fundamentais em cada área funcional da organização, conforme se observa no gráfico 01: medição de desempenho.

RC: 98782

Disponível em: https://www.nucleodoconhecimento.com.br/administracao/gestao-deestoques 
Gráfico 01: Média - Desempenho por Área Funcional

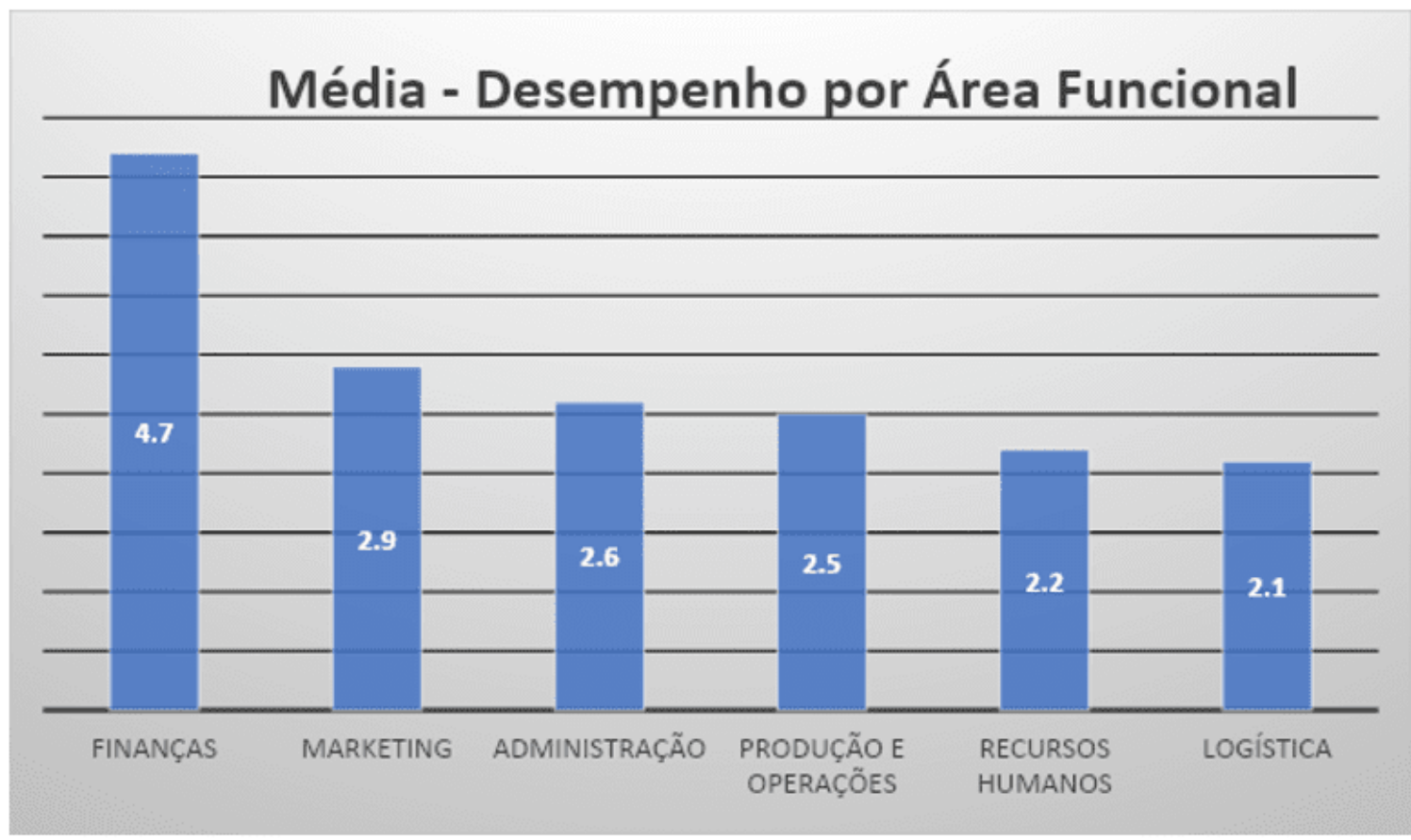

Fonte: Elaborado pelos autores do diagnóstico mediante questionário aplicado. 2021.

Segundo o observado na classificação dos setores, constata-se que na Empresa Samaúma Distribuidora de Autopeças LTDA. - SPE, o melhor desempenho inicia-se nas Finanças, sequenciando-se o Marketing, Administração, o setor de Produção e Operações, bem como os Recursos Humanos e a área de Logística apresentandose como a mais crítica da instituição.

Declara-se que este departamento apresenta maior necessidade de diligentes resoluções, gerando assim, maior eficiência no desempenho. Conforme o gráfico 1, nota-se que a Logística interna exige minuciosas averiguações, onde abordando o organizacional com práticas específicas, maiores resultados são facilmente possíveis.

RC: 98782

Disponível em: https://www.nucleodoconhecimento.com.br/administracao/gestao-deestoques 
Quadro 01: Logística

\begin{tabular}{|c|c|c|c|c|c|c|}
\hline \multicolumn{2}{|c|}{ ÁREA FUNCIONAL } & \multicolumn{5}{|c|}{ NÍVEL OU GRAU DE AVALIAÇÃO } \\
\hline \multicolumn{2}{|c|}{ LOGÍSTICA } & Ponto & Ponto & Ponto & Ponto & Ponto \\
\hline 1 & $\begin{array}{l}\text { Disponibiliza-se a empresa de } \\
\text { veículos adequados para entregas }\end{array}$ & & & & & $\mathrm{X}$ \\
\hline 2 & $\begin{array}{l}\text { Possibilita-se a organização o uso } \\
\text { de Controles de Estoque }\end{array}$ & & & & & $\mathrm{X}$ \\
\hline 3 & $\begin{array}{l}\text { Nota-se que as embalagens e } \\
\text { suprimentos são apropriados }\end{array}$ & & & & $X$ & \\
\hline 4 & $\begin{array}{l}\text { Observa-se equipamentos para } \\
\text { manuseio de materiais }\end{array}$ & & & & & $\mathrm{X}$ \\
\hline 5 & $\begin{array}{l}\text { Propicia-se o armazém de } \\
\text { iluminação, climatização e limpeza } \\
\text { adequadas }\end{array}$ & & & $X$ & & \\
\hline 6 & $\begin{array}{l}\text { Constata-se o armazenamento e } \\
\text { divisão ocorrem conforme solicitação } \\
\text { das filiais }\end{array}$ & & & & $X$ & \\
\hline 7 & $\begin{array}{l}\text { Proporciona-se o nível de serviço ou } \\
\text { de atendimento relativamente como } \\
\text { bom }\end{array}$ & & & $\mathrm{X}$ & & \\
\hline 8 & $\begin{array}{l}\text { Transporta-se por modo Aéreo } \\
(10 \%) \text { e Rodoviário }(90 \%)\end{array}$ & & & $X$ & & \\
\hline 9 & $\begin{array}{l}\text { Ocorre-se planejamento e controle } \\
\text { dos materiais }\end{array}$ & & & & $X$ & \\
\hline 10 & $\begin{array}{l}\text { Utiliza-se o sistema tecnológico } \\
\text { Sistematic para processar os } \\
\text { pedidos }\end{array}$ & & & $X$ & & \\
\hline
\end{tabular}

$\mathrm{RC}: 98782$

Disponível em: https://www.nucleodoconhecimento.com.br/administracao/gestao-deestoques 


\begin{tabular}{|l|l|l|l|l|l|}
\hline TOTAL $(\Sigma)$ & 0 & 0 & 12 & 6 & 3 \\
\hline MÉDIA POR GRAU (POR COLUNA) & 0 & 0 & 1,2 & 0,6 & 0,3 \\
\hline DESEMPENHO DA ÁREA $(\Sigma)$ TOTAL & 2,1 & & & & \\
\hline
\end{tabular}

Fonte: Elaborado pelos autores do diagnóstico mediante questionário aplicado. 2021.

Conforme os dados acima é possível observar que os fatores podem ser classificados desde o ponto máximo no valor 5 ao mínimo no valor 1 . Os fatores abordados desenvolveram-se por métodos específicos de coleta de dados.

No entanto, conforme dados obtidos, as melhores classificações deste setor apresentam-se com pontuação 3 , o que é de grande preocupação em decorrência da importância de tal setor. Sendo assim, existe a grande necessidade de averiguação interna, referente aos processos que envolvem a estocagem e a logística da instituição Somaza.

Diante do declarado objetiva-se a imisção de métodos que busquem recursos para alcançar-se soluções a problemática destacada, sendo de máxima prioridade o melhor desenvolvimento da área de logística. Portanto, a íntegra do problema de pesquisa é: como a inserção de técnicas japonesas de gerenciamento no Centro de Distribuição da Somaza podem desenvolver melhorias na produtividade do setor de estoque do Grupo?

\subsection{PLANEJAMENTO DE AÇÕES}

Com o firme intuito de gerar melhores métodos na estrutura logística do Centro de Distribuição (CD) do Grupo Somaza, desenvolveu-se o quadro a seguir que demonstra as Ações Interventivas propostas para a inserção de ferramentas que auxiliem os colaboradores nas atividades relacionadas ao estoque do estabelecimento. 
Quadro 02: Ações interventivas

\begin{tabular}{|c|c|c|c|c|}
\hline & Ações Interventivas & Cronologia & Duração & Custo \\
\hline 01 & 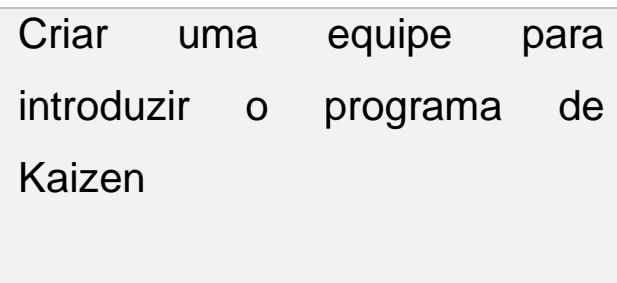 & Agosto/2021 & 30 dias & $\begin{array}{l}\mathrm{R} \$ / \text { horas } \\
\text { da mão de } \\
\text { obra } \\
\text { interna. }\end{array}$ \\
\hline 02 & $\begin{array}{l}\text { Aplicar o conceito de } 85 \text { na } \\
\text { organização do espaço físico } \\
\text { do armazém }\end{array}$ & Agosto/2021 & Indeterminado & $\begin{array}{l}\mathrm{R} \$ / \text { horas } \\
\text { da mão de } \\
\text { obra } \\
\text { interna. }\end{array}$ \\
\hline 03 & $\begin{array}{l}\text { Implementar PDCA para } \\
\text { identificar necessidades de } \\
\text { treinamento de controle do } \\
\text { estoque baseada da } \\
\text { mentalidade enxuta e no } \\
\text { conceito de 8S }\end{array}$ & Setembro/2021 & 3 Dias & $\begin{array}{l}R \$ \\
1.200,00\end{array}$ \\
\hline 04 & $\begin{array}{l}\text { Estabelecer critérios de } \\
\text { reposição dos estoques } \\
\text { baseando-se na classificação } \\
\text { ABC }\end{array}$ & Setembro/2021 & 3 Dias & $\mathrm{R} \$ 800,00$ \\
\hline 05 & $\begin{array}{l}\text { Reorganizar os } \\
\text { endereçamentos dos itens dos } \\
\text { armazéns por categorias de } \\
\text { maior giro }\end{array}$ & Outubro/2021 & 2 Semanas & $\begin{array}{l}R \$ \\
2.000,00\end{array}$ \\
\hline 06 & $\begin{array}{l}\text { Elaborar um contrato com } \\
\text { aplicativos de entrega (Uber e } \\
99 \text { Entregas) para aperfeiçoar } \\
\text { a movimentação de peças } \\
\text { entre as filiais e eventuais } \\
\text { entregas a clientes }\end{array}$ & Setembro & Permanente & $\begin{array}{l}\text { Variante } \\
\text { conforme } \\
\text { tarifa }\end{array}$ \\
\hline
\end{tabular}

RC: 98782

Disponível em: https://www.nucleodoconhecimento.com.br/administracao/gestao-deestoques 
TOTAL

$\mathrm{R} \$$

$4.000,00$

Fonte: Elaborado pelos autores do diagnóstico mediante questionário aplicado. 2021

Acima demonstra-se de forma cronológica, quais atividades podem ser inseridas no meio logístico da instituição objeto deste estudo. Com tais ações, espera-se que as falhas sejam corrigidas e o fluxo no estoque da instituição seja melhor gerido, acentuando assim a qualidade e excelência que a organização possui.

\subsubsection{FERRAMENTA DA QUALIDADE PARA IMPLEMENTAÇÃO $5 \mathrm{~W} 2 \mathrm{H}$}

Este modelo de metodologia que se formulou no Japão no ramo automobilístico é basicamente um conjunto de práticas que devem constar em um plano de ações, o qual deve ser desenvolvido rapidamente, no entanto, gerando máxima eficiência. A combinação dos números e letras refere-se na língua inglesa às iniciais dos questionamentos que formulam esta ferramenta. Sendo estas: What; Why; Who; Where; When - (5W) e How; How Much - (2H). Significando consecutivamente: O que, por que, por quem, onde e quando determinado bem ou serviço será produzido, além de como e quanto vai custar a organização e a produção deste.

De acordo com Santos et al. (2013) define-se 5W2H como uma ferramenta de teor auxiliador, empenhada em proporcionar melhor organização dos processos, metas e os métodos utilizados para atingi-los.

A inserção desta metodologia na SOMAZA, visa o melhor planejamento, organização e execução das atividades voltadas ao setor de logística do CD da organização, gerando assim o aumento da produtividade e consequentemente o faturamento.

RC: 98782

Disponível em: https://www.nucleodoconhecimento.com.br/administracao/gestao-deestoques 


\subsubsection{CRIAR EQUIPE PARA INTRODUZIR PROGRAMAS DE KAIZEN. $(5 \mathrm{~W} 2 \mathrm{H})$}

Constatou-se com base nos dados obtidos a necessidade de estabelecer um programa de melhoria contínua nos processos para melhor organização dos produtos para revenda, dispostos no armazém. A empresa estudada já detém uma robusta carteira de clientes, porém para aumentar o nível da qualidade dos serviços prestados necessita aprimorar os processos internos de estocagem. Percebe-se na organização que se tornou necessário evoluir nas práticas de gerenciamento dos estoques de revenda. No quadro 3 apresenta-se o planejamento para introdução do programa Kaizen na empresa.

Quadro 03: Criar uma equipe para introduzir o programa de Kaizen

\section{Criar uma equipe para introduzir o programa de Kaizen.}

\begin{tabular}{|l|l|l|}
\hline What & O quê? & $\begin{array}{l}\text { Introduzir a cultura de melhoria contínua nos processos } \\
\text { logísticos da empresa. }\end{array}$ \\
\hline Why & Por quê? & Para maximizar os resultados \\
\hline Where & Onde? & Armazém do centro de distribuição \\
\hline When & Quando? & Primeira semana de agosto de 2021 \\
\hline Who & Quem? & Departamento logístico \\
\hline How & Como? & $\begin{array}{l}\text { Brainstorming com as equipes envolvidas para levantamento } \\
\text { das etapas que podem ser otimizadas. }\end{array}$ \\
\hline How & Quanto? & $\mathrm{R} \$$ / horas da mão de obra interna utilizada no projeto \\
Much & & \\
\hline
\end{tabular}

Fonte: Autores, 2021.

Conforme o quadro 3 acima, foi apresentado um plano de ação para introdução da filosofia Kaizen no gerenciamento dos armazéns. Será desenvolvido no armazém do centro de distribuição e acontecerá na primeira semana de agosto/2021. O departamento gerencial de logística ficará responsável por colocar em prática a ação

RC: 98782

Disponível em: https://www.nucleodoconhecimento.com.br/administracao/gestao-deestoques 
proposta, por meio do levantamento de necessidades de treinamento sobre as práticas de Kaizen e seu processo de introdução. Obedecendo às premissas do Kaizen espera-se investir apenas em horas de treinamento sobre a filosofia e seu processo de introdução.

\subsubsection{APLICAR O CONCEITO DE 8S NA ORGANIZAÇÃO DO ESPAÇO FÍSICO DO ARMAZÉM. (5W2H)}

A evolução das técnicas de housekeeping serão ferramentas utilizadas como um ponto de corte na introdução do Kaizen. Constata-se que estes os fatores relativos ao 8S são fatores de melhoria a serem trabalhados no programa Kaizen.

Quadro 04: Aplicar o conceito de 8S na organização do espaço físico do armazém

\section{Aplicar o conceito de $8 \mathrm{~S}$ na organização do espaço físico do armazém}

\begin{tabular}{|l|l|l|}
\hline What & O quê? & Treinar equipe e introduzir o conceito. \\
\hline Why & Por quê? & Para criar condições de introdução do programa Kaizen. \\
\hline Where & Onde? & Armazém do centro de distribuição \\
\hline When & Quando? & Segunda semana de agosto 2021 \\
\hline Who & Quem? & Departamento comercial \\
\hline How & Como? & $\begin{array}{l}\text { Criar plano de ação para as ações demandadas pelo } \\
\text { brainstorming. }\end{array}$ \\
\hline How & Quanto? & R\$ / horas da mão de obra interna utilizada no projeto \\
\hline Much & & \\
\hline
\end{tabular}

Fonte: Autores, 2021

Conforme o quadro 4 acima, foi apresentado um plano de ação para aplicar as técnicas do $8 \mathrm{~S}$ na organização estudada. O Programa será desenvolvido na própria empresa, onde acontecerá na segunda semana de agosto/2021. O departamento logístico será o responsável por introduzir a proposta. Espera-se ao final desta etapa

RC: 98782

Disponível em: https://www.nucleodoconhecimento.com.br/administracao/gestao-deestoques 
construir um ambiente mais proativo e saudável criando uma favorável situação para evolução das etapas do processo de Kaizen.

\subsubsection{ESTABELECER CRITÉRIOS DE REPOSIÇÃO DOS ESTOQUES BASEANDO-SE NA CLASSIFICAÇÃO ABC. (5W2H)}

A utilização da ferramenta $A B C$ pretende oportunizar aos gestores estabelecer um critério otimizado de aquisição que possibilite à empresa reduzir o investimento em inventários sem perder o diferencial competitivo da empresa que é a disponibilidade de produtos.

Quadro 05: Estabelecer critérios de reposição dos estoques baseando-se na classificação ABC

\section{Estabelecer critérios de reposição dos estoques baseando-se na classificação ABC}

\begin{tabular}{|l|l|l|} 
What & O quê? & $\begin{array}{l}\text { Estabelecer critérios diferenciados para aquisição dos itens de } \\
\text { acordo com a classificação por valor } x \text { giro de estoque. }\end{array}$ \\
\hline Why & Por quê? & $\begin{array}{l}\text { Para evitar altos estoques de produtos de baixo giro e alto } \\
\text { valor de custo }\end{array}$ \\
\hline Where & Onde? & Departamento de Compras da empresa. \\
\hline When & Quando? & Terceira semana de agosto 2021 \\
\hline Who & Quem? & Gerência geral da organização \\
\hline How & Como? & $\begin{array}{l}\text { Utilização do recurso já disponível no sistema de ERP da } \\
\text { empresa }\end{array}$ \\
\hline How & Quanto? & $\mathrm{R} \$ 800,00$ \\
Much & & \\
\hline
\end{tabular}

Fonte: Autores, 2021.

As ações propostas no quadro 5, a introdução da classificação $A B C$ nos processos de compras visa otimizar o capital investido em estoque de produto de revenda,

RC: 98782

Disponível em: https://www.nucleodoconhecimento.com.br/administracao/gestao-deestoques 
pretende-se concluir os primeiros resultados na terceira semana de agosto/2021, com previsão de término na mesma semana e as aquisições a partir desta data devem ser feitas obedecendo o novo critério.

Esta ação terá o custo de $R \$ 800,00$ para treinamento da utilização do ERP e pretende-se reduzir o custo dos inventários, aumentar a disponibilidade de itens e eliminar a obsolescência de itens que foram eventualmente adquiridos sem critérios organizados de compras. O Gerente Geral da organização será responsável por validar as etapas e homologar a proposta.

\subsubsection{REORGANIZAR OS ENDEREÇAMENTOS DOS ITENS DOS ARMAZÉNS POR CATEGORIAS DE MAIOR GIRO. (5W2H)}

Para manter um processo evolutivo na organização e constante, torna-se necessário que a empresa busque aumentar a eficiência no tempo de atendimento dos clientes. Organizando os estoques e aproximando da expedição os produtos que tenham o maior giro, permitem redução de tempo de atendimento dos clientes e também a redução dos recursos humanos disponibilizados na operação.

Quadro 06: Reorganizar os endereçamentos dos itens dos armazéns por categorias de maior giro

Reorganizar os endereçamentos dos itens dos armazéns por categorias de maior giro.

\begin{tabular}{|l|l|l|}
\hline What & O quê? & Reorganizar os endereçamentos dos estoques. \\
\hline Why & Por quê? & Para reduzir o tempo de separação de mercadorias. \\
\hline Where & Onde? & Almoxarifado central \\
\hline When & Quando? & Primeira semana de setembro 2021 \\
\hline Who & Quem? & Departamento Logístico \\
\hline How & Como? & $\begin{array}{l}\text { Organizar a localização dos produtos baseando-se em seu } \\
\text { giro. }\end{array}$
\end{tabular}

How Quanto? $\mathrm{R} \$ 2.000,00$

RC: 98782

Disponível em: https://www.nucleodoconhecimento.com.br/administracao/gestao-deestoques 


\section{Much}

Fonte: Autores, 2021.

Apresenta-se no quadro 6 acima, um processo de melhoria contínua, ao qual após sua introdução espera-se reduzir o valor financeiro dos inventários e dotar os estoques como um conjunto de itens que tenham alto giro buscando-se acréscimo de faturamento e maior satisfação dos clientes pela qualidade de serviços oferecidos. O departamento logístico ficará responsável por colocar em prática a ação proposta. Esta ação terá um custo total de $R \$ 2 \cdot 000,00$. Novos processos sempre podem trazer insegurança aos colaboradores, portanto é necessário divulgar os benefícios esperados com as ações.

\subsubsection{ELABORAR UM CONTRATO COM APLICATIVOS DE ENTREGA. (5W2H)}

Ressalta-se a necessidade de estabelecer um contrato com empresas terceirizadas de transporte de mercadorias, para agilizar o processo de suprimento das filiais com a maior agilidade possível, visto que, a impossibilidade de manter altos estoques de produtos em todas as filiais, principalmente para itens de maior valor agregado. Abaixo apresenta-se a proposta de efetivação do processo.

Quadro 07: Elaborar um contrato com aplicativos de entrega

\section{Elaborar um contrato com aplicativos de entrega}

\begin{tabular}{|ll|l|}
\hline What & O quê? & Padronizar a movimentação de peças entre filiais \\
\hline Why & Por quê? & Para melhoria na qualidade de suprimento das filiais \\
\hline Where & Onde? & Aplicado em todas as filiais \\
\hline When & Quando? & Segunda semana de setembro 2021 \\
\hline Who & Quem? & Gerência administrativa da empresa. \\
\hline How & Como? & Contrato estruturado e valorado para execução dos serviços \\
\hline How & Quanto? & Custo operacional mensal \\
\hline
\end{tabular}

RC: 98782

Disponível em: https://www.nucleodoconhecimento.com.br/administracao/gestao-deestoques 


\section{Much}

Fonte: Autores, 2021

Conforme o quadro 7 acima, espera-se com esta ação eliminar os processos desorganizados e gerar melhor movimentação de materiais entre a matriz e as filiais. Esta operação buscará aumentar a acuracidade dos estoques, padronizando também os métodos e controles de movimentação de itens.

\section{CONSIDERAÇÕES FINAIS}

O alto índice de inovação e modificações constantes que ocorrem diariamente em todos os setores são os pontos mais fortes de incidência de competitividade, instituições que se adequam, com o tempo perdem seus postos no mercado. No segmento de autopeças não diferiria, há grandes percalços que o mercado brasileiro enfrenta. Mesmo com o grande desenvolvimento do ramo produtivo de automotores, o segmento que deveria ser companheiro deste, não conseguiu acompanhá-lo. No entanto, por tratar-se de um setor que depende de outro, a cada nova modificação tecnológica ocorrendo em veículos, transcreve-se em uma nova oportunidade ao mercado de autopeças, o ramo cresce continuamente a seu próprio ritmo.

Conforme o abordado na Diagnose Organizacional aplicada na Samaúma Distribuidora de Autopeças LTDA. - SPE e os dados averiguados no gráfico de setores, verificou-se que a área logística da instituição se aponta como crítica, a qual necessita de reparos em tópicos específicos. A problemática abordada busca compreender como a inserção de técnicas japonesas de gerenciamento no Centro de Distribuição da Somaza podem desenvolver melhorias na produtividade do setor de estoque do Grupo?

Mediante a isto, propõe reestruturar os estoques de modo e aplicam-se as ferramentas metodológicas descritas por KAIZEN, conceito 8S, PDCA e Curva ABC. Deste modo, com o plano de ações apresentado contribuiu-se a melhor comunicação entre setores, ao gerenciamento e maximização dos processos, em

RC: 98782

Disponível em: https://www.nucleodoconhecimento.com.br/administracao/gestao-deestoques 
que a reestruturação dos estoques passou a produzir giro de estoque nos armazéns, aumentando assim, a lucratividade da organização.

Em suma, agregar valores aos produtos oferecidos pela instituição é o que as difere da concorrência, transformar o gerenciamento dos processos para estes serem efetuados com destreza proporciona melhor desenvolvimento das atividades dos setores e garante maior satisfação dos consumidores, o que promove a maximização dos ganhos da instituição.

\section{REFERÊNCIAS}

CARDOSO, M. F. Capital intelectual e a inovação tecnológica: uma análise da relação contratual cliente/fornecedor. - São Leopoldo: Repositório Digital da Biblioteca da Universidade do Vale do Rio de Sinos - UNISINOS, 2012. Disponível em: <http://www.repositorio.jesuita.org.br/handle/UNISINOS/4608>. Acesso em: agosto de 2021.

CARVALHO, J. P. P. Logística e gestão da cadeia de abastecimento. - Porto: Repositório Científico do Instituto Politécnico do Porto, 2013. Disponível em: <https://recipp.ipp.pt/handle/10400.22/4592>. Acesso em: agosto de 2021.

CUNHA, O. M. C. Implementação da metodologia 5 s e análise de tempos e métodos numa linha de montagem de carroçarias. - Coimbra: Repositório científico da Faculdade de Ciências e Tecnologia - Universidade de Coimbra FCTUC, 2012. Disponível em: <https://estudogeral.sib.uc.pt/handle/10316/20555>. Acesso em: agosto de 2021.

FORNELOS, J. D. L. F. Implementação do Kaizen Diário numa Fábrica de Louça Metálica. - Porto: Faculdade de Engenharia da Universidade do Porto, 2016. Disponível em: $<$ https://repositorioaberto.up.pt/bitstream/10216/84383/2/137685.pdf>. Acesso em: agosto de 2021. 
GODOY, L. de. A logística na destinação do lodo de esgoto. - Americana: Faculdade de Tecnologia de Americana, 2013. Disponível em: $<$ http://ric.cps.sp.gov.br/handle/123456789/1269>. Acesso em agosto de 2021.

ITO, O. M. Aplicando o evento kaizen na redução do ciclo de desenvolvimento de programas de usinagem para máquinas cnc. - Taubaté: Universidade de Taubaté. 2012.

Disponível em: $<$ http://repositorio.unitau.br:8080/jspui/handle/20.500.11874/474>. Acesso em: agosto de 2021.

KURIBAYASHI, B. A. Aplicação da metodologia kaizen: um estudo de caso em uma moldadora para o processo de fundição. - Jaraguá do Sul: Repositório Institucional do Instituto Federal de Educação, Ciência e Tecnologia de Santa Catarina. 2018. Disponível em: <https://repositorio.ifsc.edu.br/handle/123456789/434>. Acesso em: agosto de 2021.

LOOS, M. J.; FONTES, É. G. Aplicação da metodologia Kaizen: um estudo de caso em uma indústria têxtil do centro oeste do Brasil. Revista Espacios. p. 569-584, ed: 21, $2017 . \quad$ Disponível em: <http://es.revistaespacios.com/a17v38n21/a17v38n21p06.pdf>. Acesso em: agosto de 2021.

MAGNO, C. O. V.; FERREIRA, R. U. Logística enxuta: distribuição com base na técnica lean thinking. - Porto: Anais do I Congresso Mundial de Engenharia de Sistemas e Tecnologia da Informação. p. 126-130, 2013. Disponível em: $<$ https://copec.eu/congresses/wcseit2013/proc/works/27.pdf>. Acesso em: agosto de 2021.

MARTELLI, L. L.; DANDARO, F. Planejamento e controle de estoque nas organizações. Revista Gestão Industrial. p. 170-185, ed: 02, 2015. $<$ https://periodicos.utfpr.edu.br/revistagi/article/view/2733>. Acesso em: agosto de 2021. DOI: 10.3895/gi.v11n2.2733.

RC: 98782

Disponível em: https://www.nucleodoconhecimento.com.br/administracao/gestao-deestoques 
MATSUMOTO, S. E.; CULCHESK, A. S. Implantação do programa 8s em uma empresa do ramo de confecção. - Maringá: Trabalhos de Conclusão de Curso do DEP. p. 01-38, ed: 01, 2017. Disponível em: <http://www.dep.uem.br/gdct/index.php/dep_tcc/article/view/348>. Acesso em: agosto de 2021.

MENEZES, A. H. N.; et al. Metodologia científica: teoria e aplicação na educação a distância. - Petrolina: Fundação Universidade Federal do Vale do São Francisco, $1^{\text {a }}$ ed. Digital, 2019.

MUNARETTO, L. F.; et al. Um estudo sobre as características do método Delphi e de grupo focal, como técnicas na obtenção de dados em pesquisas exploratórias. Revista de Administração da Universidade Federal de Santa Maria. p. 9-24, ed.: $01,2013.2$ Disponível em: <https://www.redalyc.org/articulo.oa?id=273428927002>. Acesso em: agosto de 2021.

MURBACK, F. G. R.; DANIEL, É. A. D. Levantamento bibliográfico do uso das ferramentas da qualidade. Revista do Curso de Administração / PUC Minas Gestão e $\quad$ Conhecimento. $2014 . \quad$ Disponível em: <https://www.pucpcaldas.br/graduacao/administracao/revista/artigos/v2014/Artigo16 2014.pdf>. Acesso em: agosto de 2021.

PÁDUA, M. A. de; GARCIA, G. F. R. Logística enxuta: a abordagem lean no setor de expedição. - Minas Gerais: Centro Universitário do Sul de Minas - UNIS, 2019. Disponível em: <http://192.100.247.84/handle/prefix/1207>. Acesso em: agosto de 2021.

PASCHOARELLI, L. C.; et al. Características qualitativas, quantitativas e qualiquantitativas de abordagens científicas: estudos de caso na subárea do design ergonômico. Revista de Design, Tecnologia e Sociedade. p. 65-78, ed.: 01, 2015. Acesso em: agosto de 2021.

RC: 98782

Disponível em: https://www.nucleodoconhecimento.com.br/administracao/gestao-deestoques 
PEREIRA, M. C.; LIMA, P. G. Pesquisa científica em ciências humanas: uma introdução aos fundamentos e eixos procedimentais. - Uberlândia: Navegando Publicações. $1^{\underline{a}}$ ed., 2018.

SANTANA, O. A.; ENCINAS, J. I. O trabalho científico na metodologia científica. - Brasília: Universidade de Brasília, Departamento de Engenharia Florestal. $1^{\underline{a}}$ ed., 2019.

SANTOS, A. A. M. dos; et al. Gestão da qualidade: conceito, princípio, método e ferramentas. Revista Científica Intermeio. p. 91-101, ed: 02, 2013. Disponível em: $<$ http://www.fafor.edu.br/pesquisa/arquivos/revistaintermeio_ano1_n2_set_2013.pdf\# page $=91>$. Acesso em: agosto de 2021.

SANTOS, R. dos; BRUNO, D. M. Proposta de melhoria de um sistema logístico em um almoxarifado público através da implantação da ferramenta 5s. - Ponta Grossa: Anais do IX Congresso Brasileiro de Engenharia de Produção. 2019. Disponível em: <http://aprepro.org.br/conbrepro/2019/anais/arquivos/09162019_110905_5d7f9c313 7 fbd.pdf>. Acesso em: agosto de 2021.

SANTOS, V. G. V. A filosofia just in time como otimização do método de produção. Revista eletrônica FACE. 2014. Disponível em: <http://facefaculdade.com.br/antigo/arquivos/revistas/A_filosofia_just_in_time_como_ otimizacao_de_metodo_de_producao.pdf $>$. Acesso em: agosto de 2021.

SCHNEIDER, E. M.; et al. Pesquisas quali-quantitativas: contribuições para a pesquisa em ensino de ciências. Revista pesquisa qualitativa. p. 569-584, ed: 09, 2017. Disponível em: <https://editora.sepq.org.br/rpq/article/view/157>. Acesso em: agosto de 2021.

SHITSUKA, D. M.; et al. Licenciatura em computação. Metodologia da pesquisa científica. - Santa Maria: Universidade Federal de Santa Maria. $1^{\text {a }}$ ed., 2018. 
SILVA, A. M. da; et al. Aplicação das ferramentas da qualidade: estudo de caso em pequena empresa de pintura. Revista Fatec Zona Sul - REFAS. p. 31-45, ed: 01 , 2016.

Disponível em: <http://www.revistarefas.com.br/index.php/revfateczs/article/view/70>. Acesso em: agosto de 2021.

SILVA, A. J. H. da. Metodologia de pesquisa: conceitos gerais. - Paraná: Universidade Estadual do Centro-Oeste - UNICENTRO, 2014. Disponível em: <http://repositorio.unicentro.br:8080/jspui/bitstream/123456789/841/1/Metodologiada-pesquisa-cient\%C3\%ADfica-conceitos-gerais.pdf>. Acesso em: agosto de 2021.

SILVA, E. N. et al. Proposta de Aplicação da Filosofia Kaizen em uma Empresa do Ramo de Panificação: um estudo de caso. Revista Científica H-Tec Humanidades e Tecnologia. p. 06-167, ed: 02, 2018. Disponível em: <https://www.revista.fateccruzeiro.edu.br/index.php/htec/article/view/88>. Acesso em: agosto de 2021

SILVA, R. M. R. da; OLIVEIRA, M. M. E. P. Gestão de estoque. - Cuiabá: Instituto Cuiabano de Educação, $2014 . \quad$ Disponível em: <https://www.academia.edu/download/33766581/895c3ab2654ab5a9c11b63e22780 aaf3.pdf>. Acesso em: agosto de 2021.

SOUZA, A. D.; et al. Análise da gestão de estoque de uma micro empresa de autopeças de campo Mourão-PR: uso da classificação abc dos materiais. Revista Foco. p. 21-38, ed: 01, 2015. Disponível em: $<$ https://www.researchgate.net/profile/Juliano-DominguesSilva/publication/311583962_ANALISE_DA_GESTAO_DE_ESTOQUE_DE_UMA_MI CRO_EMPRESA_DE_AUTOPECAS_DE_CAMPO_MOURAOPR_uso_da_classificacao_ABC_dos_materiais/links/5c1257b54585157ac1bf5103/A NALISE-DA-GESTAO-DE-ESTOQUE-DE-UMA-MICRO-EMPRESA-DEAUTOPECAS-DE-CAMPO-MOURAO-PR-uso-da-classificacao-ABC-dosmateriais.pdf>. Acesso em: agosto de 2021. 
SOUZA, É. M. de; RAINHO, M. J. Parcerias entre fornecedor-cliente na cadeia de suprimentos como fonte de competitividade. Pós em revista do Centro Universitário Newton. p. 78-83, ed.: 07, 2013. Disponível em: $<$ http://revistas.newtonpaiva.br/pos-em-revista/wp-content/uploads/2021/05/E0712.pdf>. Acesso em: agosto de 2021.

SPEJORIM, W.; JUNIOR, I. de B. Gestão estratégica de Armazenagem. - Curitiba: IESDE Brasil S.A., 2012.

TEZA, P. et al. Métodos, técnicas e ferramentas para inovação: o uso do brainstorming no processo de design contribuindo para a inovação. Revista Pensamento \& Realidade. p. 61-81, ed.: 01, 2017. Disponível em: $<$ https://revistas.pucsp.br/pensamentorealidade/article/view/28373>. Acesso em: agosto de 2021.

TREINTA, F. T. et al. Metodologia de pesquisa bibliográfica com a utilização de método multicritério de apoio à decisão. Revista Produção. p. 508-520, ed: 03, 2014.

<https://www.scielo.br/j/prod/a/9BprB4MFDXfpSJqkL4HdJCQ/?lang=pt>. Acesso em: agosto de 2021. DOI: https://doi.org/10.1590/S0103-65132013005000078.

VAGO, F. R. M. et al. A importância do gerenciamento de estoque por meio da ferramenta curva abc. Revista Sociais e Humanas - CCSH / UFSM. p. 638-655, ed.: $\quad 03, \quad 2013.2$ Disponível em: $<$ https://periodicos.ufsm.br/index.php/sociaisehumanas/article/view/6054>. Acesso em: agosto de 2021.

ZORZENON, R. Práticas de gestão da qualidade na relação cliente-fornecedor em produtos eletrônicos. - São Carlos: Universidade Federal de São Carlos. 2019.

Enviado: Setembro, 2021.

Aprovado: Outubro, 2021.

RC: 98782

Disponível em: https://www.nucleodoconhecimento.com.br/administracao/gestao-deestoques 